American Journal of Scientific Research and Essays
(ISSN:2475-7527)

\title{
Comparative Study on Conventional and Molecular Diagnostic Tools for Genital Tuberculosis Correlating with Infertility in Indian Women
}

\author{
Gargi Kumari ${ }^{1,2}$, Amit Mani Tiwari ${ }^{1}$, Divya Goel $^{2}$ and Sanjay Mishra ${ }^{1 *}$
}

1Department of Biotechnology, IFTM University, Lodhipur Rajput, Delhi Road (NH 24), Moradabad 244102, UP, India; 2 Department of Clinical Biochemistry \& Pathology, Sri Sai Hospital, Delhi Road, Near Loco Shed Bridge, Moradabad 244 001, U.P., India

\begin{abstract}
Mycobacterium tuberculosis, the etiological agent for tuberculosis, has been comprehensively studied for over a century now. But the disease still remains a major public health concern today in the $21^{\text {st }}$ century. The precised and authenticated diagnosis is mandatorily pre-requisite to proper medication and cure of tuberculosis that specifically interferes and thus complicating physiological and biochemical mechanism of setting pregnancy in Indian women ranging between the age of 18-40 years. Various combinations of conventional and modern diagnostic tools were considered and monitored for the best possible option. Data obtained from the present study provides new insights into PCR with modified and advanced protocol likely to be competent as a novel molecular diagnostic technique for rapid and précised diagnosis of genital tuberculosis causing infertility in developing countries.
\end{abstract}

Key words:

Amenorrhea, Endoscopy-laparoscopy, Genital tuberculosis, Hysteroscopy, Menorrhagia, Mycobacterium tuberculosis, Oligomenorrhea, PCR

\section{${ }^{*}$ Correspondence to Author:}

Sanjay Mishra, Professor Department of Biotechnology, IFTM University, Delhi Road (NH 24), Moradabad 244 102, UP, India, Mobile: +91-9837096059, Email: sanjaymishra@iftmuniversity.ac.in

How to cite this article:

Kumari et al. Comparative Study on Conventional and Molecular Diagnostic Tools for Genital Tuberculosis Correlating with Infertility in Indian Women. American Journal of Scientific Research and Essays, 2016,1(1): 0001-0013.

\section{eSciencePublisher}

eSciPub LLC, Houston, TX USA. Website: http://escipub.com/ 


\section{Introduction}

Mycobacterium tuberculosis, the etiological agent for tuberculosis, has been extensively studied for over a century now. But the disease still remains a major public health concern today in the $21^{\text {st }}$ century. Despite the availability of anti-tubercular chemotherapy tuberculosis still remains a major health problem and is the leading cause of morbidity and mortality in many developing/ resource-poor countries. Despite the efforts that are being made to control tuberculosis worldwide, countless numbers of people die with every passing year [1]. Control of the disease is complicated by the fact that one-third of the world's population is latently infected with tuberculosis. An estimated $5-10 \%$ of the latently infected population develops active disease during its lifetime while the rest act as reservoir of pathogen thus making the disease control a significant challenge [2].

In addition, the difficulty in co administration of the anti-TB and anti-HIV drugs as a result of drug- drug interactions is well established. In addition, tuberculosis is difficult to diagnose in HIV-positive subjects as smear microscopy, a test widely used in developing countries fails to detect TB in $80 \%$ HIV-positive cases. Spread of drug resistant strains poses new challenges for prevention and control of this deadly disease as the present therapy fails to work on the drug resistant strains. Unless we act promptly and aggressively, this emerging global health threat will spiral, threatening to return to the pre-antibiotic era. Failure to develop programs to diagnose and treat such patients now will be more costly in the future, leading to increased incidence, greater residence, and more deaths. Non-availability of domestic funding in developing countries is again a fall back in the disease control. Early, accurate diagnosis and immediate curative treatment, under proper supervision to ensure that drugs are taken for the appropriate duration, is the key to disease control. Among various clinical presentations of tuberculosis, female genital tuberculosis poses serious concern throughout the world because of various associated complications like oligomenorrhea, amenorrhea, primary or secondary infertility, chronic pelvic pain, pelvic mass and significant mortality [3-7]. The disease is being increasingly recognised as a notable cause of infertility in recent years. Infertility is otherwise a common problem but only the couples afflicted with it can understand the social stigma, psychological stress and trauma behind it. The true incidence of the disease remains unknown as the disease poses diagnostic difficulties mainly because the primary symptoms are usually non-characteristic [8, 9]. Infertility is a well-known sequel [10].

Histopathological examination by haematoxylin and eosin for granulomatous tissue reactions compatible with tuberculosis infection is usually inconclusive, as reported earlier [11]. Over the last decade, polymerase chain reaction (PCR) has emerged as a rapid, sensitive and specific molecular method for detection of mycobacterial DNA by amplifying $65 \mathrm{kDa}$ protein-encoding gene, $38 \mathrm{kDa}$ antigen coding gene, and the IS6110 and mpt64 gene in both pulmonary and extra-pulmonary samples, as reported by various authors [12-18]. Subclinical disease or latent tuberculosis infection might give a positive result in PCR, but this is considered insignificant as prompt diagnosis is essential for averting permanent damage to genital organs and consequent infertility. Endoscopic procedures like laparoscopy and hysteroscopy are widely used for investigation of infertile women [1921]. PCRs for detection and identification of mycobacteria in clinical specimens have been developed and evaluated [19, 20], but mRNA-based assay offers great promise in differentiating between live and dead bacilli as the average half-life of bacterial mRNA is 3 min [22]. Thus as mRNA is more easily destroyed than DNA, itcan distinguish viable from non-viable organism.

Based on the aforesaid facts, the present study was undertaken to assess the utility of PCR in definitive diagnosis of tuberculosis in Indian infertility patients in conjunction with endoscopic procedures-laparoscopy and/hysteroscopy and conventional tests (smear and culture based on the radiometric BACTEC system). Also, considering the clinical importance of multi-drug resistance 
in genital tuberculosis we planned to investigate all genital tuberculosis positive cases for Rifampicin and Isoniazid resistance by automated DNA sequencing of rpo $B$, kat $G$ and inh $A$ genes.

\section{Materials and Methods}

Study subjects: A total of 700 females of child-bearing age attending the infertility Outpatient Department were screened at the IVF and Reproductive Biology Centre, Department of Gynaecology, MM Diagnostics and Sri Sai Hospital, Moradabad, India between 2012 and 2015. The ethical committee of MM Diagnostics, Moradabad approved the study. Informed consent was obtained from the patients included in this study.

Clinical cases: Out of 700, 400 females were finally recruited on the basis of inclusion and exclusion criteria.Infertile females presenting with the following findings were included for the study: (i) women between the age group 18 and 45 years; (ii) women with primary and secondary infertility; (iii) women presenting with unexplained infertility. Whereas exclusion criteria were as (i) women with previous history of genital tuberculosis; (ii) women with partner (male factor) infertility; (iii) women who refused to give consent for the study. Samples from 100 healthy fertile females were included to serve as controls. These samples were collected from females attending the family planning OPD for interval ligation and from females visiting the gynaecology OPD with complaints of menstrual irregularities etc. Further, Twenty-five known AFB cultures from different clinical forms of tuberculosis from Tuberculosis Laboratory MM Diagnostics, Moradabad were taken for comparison with molecular tests to ensure the performance of the tests. Diagnosis was achieved through a comprehensive evaluation on the basis of detailed clinical history, physical examination, biochemical investigations, molecular and laparoscopic evaluation. Provisional diagnosis was made through high index of suspicion based on the detailed clinical history.

Laproscopy: All patients underwent diagnostic endoscopy-laparoscopy and/ or hysteroscopy under general anesthesia post menstrually using the three puncture technique. During the procedure, features such as tubal blockage/patency, presence of tubercles, peri-tubal and/or peri-ovarian adhesions, granulomas, tubo-ovarian mass, beaded tubes, cornual blockage, caseation, hydrosalpinx, sacculated tubes, signs of chronic inflammation, pelvic inflammatory disease etc were precisely considered.

Conventional coordinated with Molecular diagnostic tests: Menstrual Blood (MB) was taken in the secretory phase of the menstrual cycle for the second day. Menstrual Blood sampling was taken either during Menstrual cycle second Day in a sterile container with normal Saline as a separate procedure. For laboratory processing, the sample will be immediately transported to the tuberculosis and molecular diagnostic laboratory at the MM diagnostics Laboratory Moradabad for further testing and stored at room temperature for conventional tests and at $-80^{\circ} \mathrm{C}$ for molecular tests.

(a) AFB smear. Menstrual Blood sample was obtained in normal saline in sterile container. Sample was stored at room temperature till further analysis. MB sample was ground with sterile mortar and pestle in small quantity of PBS/normal saline. One smear of each specimen was made by spreading the specimen over $2-3 \mathrm{~cm}$ in size and is neither too thick nor too thin .The optimum thickness of the smear could be assessed by placing the smear on a printing matter enabling the print readable through the smear. Smear Preparation was done near a flame. This was required, as six inches around the flame considered as a sterile zone which coagulates the aerosol raised during smear preparation. Allowed the slide to air dry for 15 to $30 \mathrm{~min}$, and fixed the slide by passing it over a flame 3-5 times for 3-4 seconds each time. The smear was then stained employing the modified protocol of Ziehl-Neelsen (ZN) staining as per protocol described in earlier study [23]. Acid fast bacilli (AFB) were observed as red, beaded rods when examined by $\mathrm{ZN}$ stain under oil immersion $(100 \mathrm{X})$ lens. The smears were then graded depending on the number of bacilli observed in the stained 
smear under oil immersion objective lens of light microscope. At least 100 fields were examined before reporting a smear as negative. A repeat smear was made in case of doubtful report and was examined again.

(b) AFB culture: Specimen $(0.5 \mathrm{ml})$ was inoculated in BACTEC (BBL MGIT) medium tube contains modified Middlebrook $7 \mathrm{H} 9$ broth base for BACTEC Micro MGIT culture system. The positive cultures were further processed for drug sensitivity by BACTEC MGIT TB system and strain identification was done by $p$-nitro- $\alpha$-acetylamino- $\beta$ hydroxy-propiophenone (NAP) test using the technique described recently by a research group [24].

(c) Molecular characterization: Polymerase chain reaction process was performed following steps in sequence as

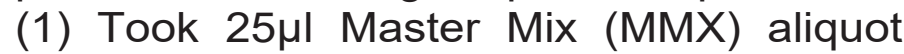
in PCR tubes and allowed it to thaw totally if stored in $-20^{\circ} \mathrm{C}$; (2) Mixed with gentle finger tapping and span shortly to settle down MMX to the bottom of PCR tube; (3) Marked on the tube based on sequence of DNA sample and positive control; (4) Added $25 \mu \mathrm{l}$ of isolated DNA template and negative control to the MMX, reaching to final volume $50 \mu \mathrm{l}$ for reaction; (5) Pipetted up and down to mix DNA template with MMX; (6) Span for a second to bring down reaction mixture to the bottom of PCR tube; (7) Kept all tubes into thermal cycler block, already switched on $5 \mathrm{~min}$ before starting reaction for auto calibration; (8) Set the program for implication for 40 cycles (Table 1). After completion of amplification keep PCR amplified product in refrigerator at $4^{\circ} \mathrm{C}$ until the detection of amplified product. In order to detect the amplified product, a known molecular weight marker (100bp DNA ladder) was loaded into the first well of $1.6 \%$ agarose gel followed by loading of $20 \mu$ l of PCR product into each well along with $4 \mu \mathrm{l}$ of gel loading buffer. Positive and negative controls were precisely loaded with the samples. Electrophoresis was carried out at $100-150 \mathrm{Volt}$ ( 5 to $8 \mathrm{~V} /$ $\mathrm{cm}$ for $20 \mathrm{~cm}$ gel) until the bands in the molecular weight marker were resolved. Later on the gel was examined under UV light $(302 \mathrm{~nm})$ on ULTRALUM Electronic UV-Trans-illuminator gel documentation system for the presence of 240 base pair PCR product and photographed.

\section{Results}

On the basis of detailed history, the study subjects (400 infertile females fulfilling inclusion criteria) were categorized with regard to their demographic profile, type of infertility and duration of married life. Patients were also categorized according to their gynaecological symptoms, menstrual disturbance, history of contact or past history of tuberculosis and history suggestive of active disease. Findings of molecular tests (DNA PCR, mRNA-based RT-PCR, and realtime PCR monitoring in the drug resistant genes) were correlated with a cascade of clinical profile/laparoscopic findings and pregnancy outcome following diagnosis and anti-tubercular treatment.

Demographic profile of study subjects: When the educational and professional/ economical background of the patients was compared, it was found that maximum patients $(45 \%)$ belonged to middle strata of the society while $35 \%$ and $20 \%$ patients belonged to lower and higher strata of the society as shown in Table 2 .

Details of study subjects and healthy fertile controls: The patients in the study group were between the age group 18 and 40 years (Table 3 ). The mean age of the patients was observed about 28 years with a standard deviation of 4.7 years. On analysis, we found that maximum

number of study subjects $(40 \%)$ belonged to the age group 26-30 years suggestive of the female genital tuberculosis probably affecting females in their early reproductive age. The duration of marital life ranged between 1.5 to 17 years. The mean deviation of marital life was 7.2 years with a standard deviation of 3.5 years.

Type of infertility: Primary infertility was noticed in 274 (68.5\%) women, while 126 $(31.5 \%)$ women had secondary infertility (Table 4). Among the patients with secondary infertility, $15.2 \%$ had previous living issue, $45.4 \%$ had previous abortions, and 15.3\% had ectopic pregnancy.

Gynaecological symptoms: In the present study, about $52 \%$ patients only had infertility and did not have any gynaecological 
Table 1: Sequence of temperature in PCR set up.

\begin{tabular}{|l|l|l|l|}
\hline Temperature ${ }^{\circ}(\mathrm{C})$ & Time (in min) & Cycles & Activity \\
\hline $94^{\mathrm{O}} \mathrm{C}$ & 6 & 1 & Initial Denaturation \\
\hline $94^{\mathrm{O}} \mathrm{C}$ & 1 & 40 & Denaturation \\
\hline $55^{\mathrm{O}} \mathrm{C}$ & 1.5 & & Annealing \\
\hline $72^{\mathrm{O}} \mathrm{C}$ & 1.5 & & Elongation \\
\hline & & & Holding \\
\hline $4^{\mathrm{O}} \mathrm{C}$ & & & \\
\hline
\end{tabular}

Table 2: Socio-economic status of the study subjects.

\begin{tabular}{|c|c|}
\hline Socioeconomic category & \% Status of the study subjects* \\
\hline Lower & $20 \pm 4$ \\
\hline Middle & $35 \pm 6$ \\
\hline High & $45 \pm 5$ \\
\hline
\end{tabular}

* Values are mean \pm SD of five replicates.

Table 3: Age distribution of study subjects.

\begin{tabular}{|l|l|l|}
\hline Age Range (Year) & Number of cases & Percentage* \\
\hline $18-25$ & 98 & $24.5 \pm 3.5$ \\
\hline $26-30$ & 107 & $40.0 \pm 5.7$ \\
\hline $31-35$ & 160 & $26.8 \pm 3.8$ \\
\hline $36-40$ & 39 & $8.7 \pm 1.4$ \\
\hline Total & 400 & \\
\hline
\end{tabular}

${ }^{*}$ Values are mean \pm SD of five replicates.

Table 4: Type of infertility in patients.

\begin{tabular}{|l|l|l|}
\hline Type of infertility & Number of cases & Percentage* $^{*}$ \\
\hline Primary & 274 & $68.5 \pm 4.3$ \\
\hline Secondary & 126 & $31.5 \pm 2.7$ \\
\hline Total & 400 & \\
\hline
\end{tabular}

${ }^{*}$ Values are mean \pm SD of five replicates. 
symptoms. Maximum patients $(63.5 \%)$ had normal menstrual cycles while menstrual disturbances in the form of amenorrhea, oligomenorrhea and menorrhagia were seen in $5 \%, 23.3 \%$ and $8.2 \%$ patients, respectively (Table 5). Oligomenorrhea was the predominant menstrual disturbance observed in the subjects.

Laparoscopy results among study subjects: Results from diagnostic endoscopy (Laparoscopy) were obtained from $50 \%$ of the study subjects (Table 6). A systemic and thorough evaluation of pelvis and abdominal cavity was carried out for evidence of TB and findings such as granulomas, caseation, calcification, tubercles and flocculated as cites were looked for. The fallopian tubes were also evaluated for the presence of proximal and distal blocks and hydrosalpinx. Presence of adhesions was also noted. Pelvis and peritoneal cavity were also evaluated for presence of other pathology. Presence of fluid in Pouch of Douglas (POD) was also observed. Pelvic pathology like fibroid uterus, endometriosis, and polycysticovaries was realized as incidental findings.

Histopathological examinations: Premenstrual endometrial biopsy samples were taken and subject to histopathology. Out of the 400 women, $2 \%$ (8/400) samples showed positive for tuberculosis (Table 7 ). In these cases, the histology showed sub epithelial tissue to display multiple caseation granulomas with Langerhans giant cells and diffused and dense inflammatory infiltrate comprising lymphocytes, plasma cells and neutrophils. The impression was said to be as granulomatous being highly suggestive of tuberculosis. Another12 patients showed signs of non-tubercular endometritis. Smear and culture: Out of the 400 study samples, AFB Smear identified $2 \%(8 / 400)$ cases (Table 8). In the control group samples, though none of the samples was observed to be positive. Culture for acid-fast bacillius in BACTEC460TB systems detected $3.25 \%$ $(13 / 400)$ cases. The cultures were identified as positive within 12days and were identified as MTB on the basis of NAP test. Apart from this, 8 cultures got contaminated. Though, none of the contaminated sample was positive in AFB smear or PCR. Finally, during correlating the obtained results, it was observed that all the 37 laparoscopy positives were also DNA-PCR positive during the present study (Table 9). Of 37 laparoscopy positives, 4 which initially tested negative or uncertain in DNA- PCR twisted. Positive in repeat PCR after spiking; later confirmed with DNA sequence homology for 65k Dagene. All these 51 PCR positive samples were confirmed to be true positives by gene sequence analysis of the PCR products as reflected in Table 9.

\section{Discussion}

It is an understanding that female genital tuberculosis has an impact on the females of reproductive age group. The disease clears itself as pelvic inflammatory disease in its severely affected form with menstrual abnormalities and later infertility, and is more or less secondary to a primary lesion somewhere else. The disease often leftovers unobserved even in most of the tertiary health care set ups principally in developing countries. The factual occurrence of this significant but comparatively unnoticed form of extra pulmonary tuberculosis remnants unknown as the disease puts forward unconquered diagnostic challenges largely because the primary symptoms are usually non-specific [25]. Infertility is a distinguished sequela. Early diagnosis consistently aids to pace up the management process and noticeably decreases the time lag in beginning anti-tubercular therapy. Though, the reported occurrence of genital tuberculosis in Asian and Western countries changes between $0.7 \%$ (in Australia) and $17 \%$ (in India); the real occurrence may be greater because a great percentage of cases go unreported as a consequence of lack of responsive and precise investigations [26, 27]. Consequently, the disease is either not diagnosed or diagnosed at an advanced stage when the tubal damage has by now occurred. At this stage, the prognosis for fertility is poor in spite of treatment. The disease is also a main cause of Asherman's syndrome in India [21, 28].

Existing methods of diagnosis of genital tuberculosis in the majority of set ups largely rely on clinical parameters shared with 
endoscopic observations and the out-dated conventional microbiological tests. Though in recent years, there are innovations in culture as well as reliable molecular approaches based on certain specific correlation between genes and proteins [29, 30]. These methods are now being progressively more used in tertiary care hospitals. Thus, a number of options are available for confirming the diagnosis of pulmonary TB. The success of these tests however depends on the nature and quality of clinical specimen, principally in cases of tuberculosis of complicated anatomical sites e.g. female genital tuberculosis. None of these methods, though, offer promise in distinguishing viable from non-viable tubercle bacilli in clinically diagnosed or DNA positive cases of genital tuberculosis. Recognition of active cases of genital tuberculosis is significant because active cases may direct to more severe damage and thus early diagnosis of active genital tuberculosis may aid in timely treatment, so reducing the chance of permanent/irreversible damage (to fallopian tubes and endometrial lining). Besides, drug resistance is another global threat in such state [31, 32]. Till date, a very little information is available on the drug resistance to tubercle bacilli from genital tuberculosis. Therefore accomplishment of the drug being administered cannot be ascertained in such cases. For that reason, a consistent test, which can accurately pinpoint the drug resistance in cases of female genital tuberculosis at an early stage (before the fallopian tubes are damaged beyond recovery), is the need of the hour.

To qualify as a diagnostic test for genital tuberculosis, a protocol of early diagnosis concomitant with high sensitivity and specificity is requisite. We, thus, carriedout the current investigation to assess the suitability of PCR as a diagnostic test for female genital tuberculosis and also inter-related the observation of PCR with laparoscopy and other conventional diagnostic tests.

In the current study, we attempted to analyse the efficiency of various parameters- AFB smear, culture by BACTEC 460 TB systems, HPE, PCR and laparoscopy in the diagnosis of female genital tuberculosis and to develop a test that can be employed for prompt diagnosis of this insidious disease. The study was conducted on 400 infertile subjects; is probably the principal study targeting DNAbased diagnostics of genital tuberculosis. During this study, we also incorporated 100 healthy fertile females as controls; besides 25 AFB cultures from different clinical forms of tuberculosis for comparison to ensure the performance of DNA and mRNA-based molecular tests. All patients also underwent laparoscopy as module of the infertility workup. The diagnosis of established tubercular disease was lastly based on laparoscopy and PCR since smear and culture gave poor outcome reported as also described by various researchers $[14,15,17,18,21,29$, $33,34]$. It was noteworthy that other reasons such as chlamydial/ gonococcal infection were not doubted by the clinicians in any of the 51 DNA positive cases of our study, as more than one positive outcomeemploying laparoscopy were measured whereas questioning genital tuberculosis.

Indicating incidence of genital tuberculosis, it is frequently complicated to determine the accurate level of the problem as the disease originally presents without symptoms and due to diagnostic complications it is singled out only during the study for infertility [26]. The incidence also varies significantly according to the socioeconomic and public health conditions; thus, there is broad variation in information published from various countries. In developing countries, the incidence is also affected due to the lack of effective and specific investigations [35, 36]. In countries like USA, Australia and Western Europe, the incidence of genital tuberculosis is greater than $1 \%$ [37]. Pelvic tuberculosis is also an infrequent gynecological problem in some of the countries like Malaysia and Thailand, the published occurrence being $0.02-5 \%$ of the gynaecological cases [38, 39]. The occurrence of genital tuberculosis in infertility clinics has been reported to range from $1.5-19 \%$ in various studies [17, 40-46]. Genital tuberculosis is thus a major causative factor for tubal factor infertility in developing countries like India [21, 47, 48]. The patients considered in the present study 
Table 5: Menstrual history of the subjects.

\begin{tabular}{|l|l|l|}
\hline Type of menstrual cycle & Number of cases & Percentage $^{*}$ \\
\hline Normal & 254 & $63.5 \pm 4.3$ \\
\hline Amenorrhea & 20 & $5.0 \pm 0.5$ \\
\hline Oligomenorrhea & 93 & $23.3 \pm 1.3$ \\
\hline Menorrhagia & 33 & $8.2 \pm 0.9$ \\
\hline Total & 400 & \\
\hline
\end{tabular}

${ }^{*}$ Values are mean \pm SD of five replicates.

Table 6: Laparoscopy reports among study subjects.

\begin{tabular}{|l|l|}
\hline Laparoscopic findings & Number of patients \\
\hline Adhesions & 35 \\
\hline Beaded tube appearance & 4 \\
\hline Tubo-ovarian mass & 8 \\
\hline Tubal block (uni) & 48 \\
\hline Tubal block (bi) & 32 \\
\hline Tube absent & 8 \\
\hline Hydrosalpinx & 10 \\
\hline Frozen Pelvic & 7 \\
\hline Tubercles & 4 \\
\hline Fluid in POD & 3 \\
\hline Caseous granuloma & 5 \\
\hline Endometriosis & 10 \\
\hline Calcification & 1 \\
\hline PID & 5 \\
\hline PCOS & 200 \\
\hline Total & \\
\hline
\end{tabular}


were aged between 18 and 40 years of age. The median age of presentation was 28.5 \pm 4.9 years. Our study reflects that genital tuberculosis affects women in relatively young age group as maximum patients belonged to the age group 18-25 years of age. This indicates an agreement with the previous studies $[12,17,49]$. Young patients being affected by genital tuberculosis can becomprehensive by the fact that after adolescence, the blood supply to the genital organs is increased; and as a result, more bacilli are capable to achieve the site and cause infection. In such a state, even the dormant bacteria can get reenergized and cause infection leading to additional number of young patients getting afflicted to genital tuberculosis foremost to infertility. Laparoscopy is a significant tool in the assessment of infertility and in the diagnosis of various pelvic conditions. In women with high suspicion of genital tuberculosis, endoscopy aids to obtain microbiological samples under direct visualization, assess the extent of damage and treat the patient accordingly [50-53]. Being a symptomless disease, the symptoms in case of genital TB can vary; thus laparoscopy may prove a key tool in its affirmation [20, 21].

In-fact, DNA positives in the present study can act as denominator for calculating the efficacy of the laparoscopy that was suggestive only in 38 out of 51 DNApositive cases. If Laparoscopy is taken as clinical gold standard, the DNA PCR results of our study may be considered as the ideal laboratory gold standard, instead of commonly believed culture as the gold standard. Also, if the figure of 400 patients is taken as denominator of target population, the prevalence of genital tuberculosis in our study works-out to be $12.75 \%$. However, this can at best represent 'prevalence within the infertile females' category only, and not the prevalence of female genital TB in a particular population of females of child-bearing age. The main advantage of PCR is that it is a rapid and specific molecular technique, which permits detection of mycobacteria from both pulmonary and extra-pulmonary specimens within 4-5 h compared to culture, which has a poor detection rate and requires a minimum of 12 days to get the result [34]. Due to the high sensitivity of PCR, false positivity becomes an issue [52, 53]. In the present study, PCR was positive in all the cases with affirmative or suspicious observations on endoscopy while detecting an additional 13 cases which showed normal laparoscopic observations. This could be attributed to the fact that while laparoscopy detects conspicuous changes such as pelvic/intrauterine adhesions, tubercles, beaded tubes, grade III endometriosis with the tubes being the commonest location, subtle changes during the early stage of infection might be overlooked. Thus, an additional 13 women diagnosed with genital tuberculosis by PCR may be considered as harbouring sub-clinical or latent infection, the early diagnosis of which could have a significant role in regaining fertility.

Stringent quality control measures were adopted while carrying-out PCR. Several negative controls were interspersed between samples to avoid cross-contamination, thus preventing false positive results. The sensitivity of PCR has been questionable because of the highly sensitive nature of the technique. Various contradictory reports across the world doubt the PCR positive results. Thus, in view of these contradictions authors were very cautious in ascertaining the efficacy (sensitivity and specificity) before applying in our clinical specimens. Authors addressed this issue by employing various quality control methods. Twenty-five positives in culture controls used in the study also prove the sensitivity and specificity of the test in the diagnosis of genital tuberculosis. All the samples were subjected to gene sequence analysis and BLAST search, which further confirmed their true positivity. For ascertaining validity on expectedly negative samples, we also took samples from hundred healthy fertile females. Four percent (4/100) samples gave positive results in DNA PCR. However, none of the sample showed a positive result in mRNA-based RT-PCR indicating that these $4 \%$ positives in healthy controls may be the latent infection possibly due to the fact that tuberculosis is highly prevalent in general population as well in India. Needless 
Table 7: Data of histopathology among the study subjects.

\begin{tabular}{|l|l|l|}
\hline Histopathological type & Number of cases & Percentage $^{*}$ \\
\hline Study group (n=400) & 8 & $2.0 \pm 0.2$ \\
\hline Tubercularendometritis & 16 & $4.0 \pm 0.5$ \\
\hline Chronic endometritis & 51 & $12.8 \pm 1.3$ \\
\hline Proliferativephase & 320 & $80.0 \pm 4.0$ \\
\hline Secretoryphase & 5 & $1.2 \pm 0.1$ \\
\hline Hyperplasticendometrium & 5 & \multicolumn{2}{|l}{} \\
\hline Control group (n=100) & \multicolumn{2}{|l|}{} \\
\hline Tubercular etiology & 0 & 0 \\
\hline
\end{tabular}

${ }^{*}$ Values are mean \pm SD of five replicates.

Table 8: Positivity in AFBsmear/culture among the study as compared with control groups.

\begin{tabular}{|l|l|l|l|l|}
\hline $\begin{array}{l}\text { Endometrial } \\
\text { biopsy }\end{array}$ & Smear* & \%age & Culture* $^{*}$ & \%age \\
\hline $\begin{array}{l}\text { Study } \\
\text { subjects } \\
(n=400)\end{array}$ & 8 & 2 & 13 & 3.25 \\
\hline $\begin{array}{l}\text { Controls } \\
(n=100)\end{array}$ & 0 & 0 & 0 & 0 \\
\hline
\end{tabular}

${ }^{*}$ All AFB smear and culture were also observed to be positive in DNA-PCR.

Table 9: Comparison of DNA-PCR results with conventional tests and laparoscopy.

\begin{tabular}{|l|l|l|l|l|l|}
\hline Tests & Histopathology & Smear & Culture & Laparoscopy & DNA PCR \\
\hline Positivity & $8 / 400$ & $8 / 400$ & $13 / 400$ & $37 / 400$ & $51 / 400$ \\
\hline
\end{tabular}


to mention that nearly $10 \%$ of the world's population is latently infected with tubercle bacilli; hence 4 otherwise healthy DNA positive females could be harbouring latent/ dormant bacteria, rather than assigning these positives as false positives.

Menstrual dysfunction complaints were observed in $36 \%$ of patients. Oligomennorhea was found to have a significant correlation between PCR positive and negative women, indicating that tuberculosis bacilli cause scarring of the endometrial lining. Partial or total destruction of endometrium by the disease process resulting amenorrhea has been shown in a few cases. Gross appearance of endometrium was mostly unremarkable. In advanced cases however, ulcerative or atrophic endometrium and an obliterated endometrial cavity due to extensive intrauterine adhesions was seen on endoscopy. Endometriosis grade II was observed in $21.5 \%$ of PCR positive patients. This can be attributed to the fact that endometriosis, being an auto-immune disease, has been shown to create a defect in natural killer activity resulting in decreased cytotoxicity to autologous endometrium. This immune defect may account for the incidence of other infectious diseases including tuberculosis occurring more frequently in these women [53].

The findings of the present study reveal that PCR-based detection of $M$. tuberculosis in endometrial biopsy specimens is a sensitive technique for pre-emptive vigilance of probable reactivation for genital tuberculosis, a foremost cause of infertility in developing countries. In the absence of a gold standard, PCR may be measured a relatively better diagnostic gold standard for competent diagnosis of genital tuberculosis in view of its high sensitivity and specificity. Furthermore, since performing laparoscopy and other endoscopic procedures on every patient is not feasible in practice, the present study provides new insights into PCR with modified and advanced protocol likely to be competent as a novel molecular diagnostic technique for rapid and précised diagnosis of genital tuberculosis causing infertility in developing countries.

\section{Acknowledgement}

The present study is a part of Ph.D. program of author Gargi Kumari who is registered at IFTM University, Moradabad, India. Also, authors are grateful to Department of Clinical Biochemistry \& Pathology, Sri Sai Hospital, Delhi Road, Near Loco Shed Bridge, Moradabad 244 001, U.P., India for facilitating to successfully conduct all biochemical and pathological studies embodied in this paper. Thus, the mutual collaboration between IFTMU, Moradabad, UP, India and Sri Sai Hospital, Moradabad, UP, India is duly acknowledged.

\section{Conflict of Interest}

Authors declare no conflict of interest.

\section{References}

1. World Health Organization. Global tuberculosis control: surveillance, planning, financing. W.H.O. Report 2011. Geneva, Switzerland. http://www. who.int/tb/country/en/index.html

2. Pablos-Mendez, M.C. Raviglione, A. Laszlo, N. Binkin, H.L. Rieder and F. Bustreo, Global surveillance for anti-tuberculosis-drug resistance, 1994-1997, World Health Organization-International Union against Tuberculosis and Lung Disease Working Group on Anti-Tuberculosis Drug Resistance Surveillance. The New Eng. J. Med. 1998; 338 (23): 1641-1649.

3. N.N. Chowdhury, Overview of tuberculosis of the female genital tract. J. Ind. Med. Assoc. 1996, 94(9):345-346.

4. M.G. Martens, Pelvic inflammatory disease, In Telind's Operative Gynaecology, J. A. Rock and J. D. Thompson, Eds. 1997, Lippincott- Raven, New York, NY, USA, pp. 678-685.

5. J.B. Namavar, B. Jahromi, M.E. Parsanezhad, R. Ghane-Shirazi, Female genital tuberculosis and infertility. Int. J. Gynecol. Obstet. 2001, 75(3): 269-272.

6. T. Dam and M. Bose, Paucibacillary tuberculosis: a retrospective study. J. Ind. Med. Assoc. 2002, 100 (4): 231-233.

7. S. Chakravorty and J.S. Tyagi, Novel multipurpose methodology for detection of mycobacteria in pulmonary and extra-pulmonary specimens by smear microscopy, culture, and PCR. J. Clin. Microbiol. 2005, 43 (6): 2697- 
2702.

8. J.B. Sharma, P. Mohanrai, K.K. Roy and S.K. Jain, Increased complication rates associated with laparoscopic surgery among patients with genital tuberculosis. Int. J. Gynecol. Obstet. 2010, 109 (3): 242-244.

9. U.N. Jindal, Y. Bala, S. Sodhi, S. Verma and S. Jindal, Female genital tuberculosis: early diagnosis by laparoscopy and endometrial polymerase chain reaction. Int. J. Tuberc. Lung Dis. 2010, 14 (12): 1629- 1634.

10. L.B. Ben Youssef, H. Chelli and A. Belhadj. Current anatomo-clinical aspects of genital tuberculosis in women: Apropos of 49 cases. Journal De Gynecologie, Obstetrique Et Biologie de la Reprod. 1985, 14 (1): 59-65.

11. P. Kumar, N.P. Shah, A.Singhal,D.S. Chauhan, V.M. Katoch, S. Mittal, et al. Association of tuberculousen dometritis with infertility and other gynecological complaints of women in India. J. Clin. Microbiol. 2008; 46(12): 4068-70.

12. J. Kamerbeek, L.Schouls, A. Kolk, M. van Agterveld, D. vanSoolingen, S, Kuijper, et al. Simultaneous detection and strain differentiation of Mycobacterium tuberculosis for diagnosis and epidemiology. J. Clin. Microbiol. 1997; 35(4): 907-14.

13. S.S. Negi, S.F. Khan, S. Gupta, S.T. Pasha, S. Khare, S. Lal. Comparison of the conventional diagnostic modalities, bactecculture and polymerase chain reaction test for diagnosisof tuberculosis. Ind. J. Med. Microbiol. 2005; 23(1): 2933.

14. N.V.Bhanu, U.B. Singh, M. Chakraborty, N. Suresh, J. Arora, T. Rana, et al. Improved diagnostic value of PCR in the diagnosis of female genital tuberculosis leading to infertility. J. Med. Microbiol. 2005; 54: 927-31.

15. U.B. Singh, N.V. Bhanu, V.N. Suresh, J. Arora, T. Rana, P. Seth. Utility of polymerase chain reaction in diagnosis of tuberculosis from samples of bone marrow aspirate. Am. J. Trop. Med. Hyg. 2006; 75(5): 960-3.

16. A.A. Al-Mulhim. Laparoscopic diagnosis of peritoneal tuberculosis. Surg. Endosc. 2004; 18(12): 1757-61.

17. E. Volpi, M. Calgaro, A. Ferrero, L. Vigano. Genital and peritoneal tuberculosis: potential role of laparoscopy in diagnosis and management. J. Am. Assoc. Gynecol. Laparosc. 2004; 11(2): 26972.

18. J.B. Sharma, K.K.Roy, M.Pushparaj, S.Kumar, N.Malhotra, S.Mittal. Arch. Gynecol. Obstet.2008; 278(4): 359-64.

19. S.K. Mondal, T.K. Dutta. A tenyear clinic-pathological study of female genital tuberculosis and impacton fertility. J. Nep. Med. Assoc. 2009; 48(173): 52-7.
20. R.C. Ellis, L.A. Zabrowarny. Safer staining method for acid fast bacilli (PDF). J. Clin. Pathol.1993; 46: 559-560.

21. A.K. Maurya, V.L. Vijaya Nag, S. Kant, R.A. Singh, M.K. Kushwaha, , V. Mishra, W. Rahman, T.N. Dhole. Evaluation of an immune chromatographic test for discrimination between Mycobacterium tuberculosis complex \& non tuberculous mycobacteria in clinical isolates from extra-pulmonary tuberculosis. Ind. J. Med. Res.2012; 135: 901-906.

22. T.R.Varma. Genital tuberculosis and subsequent fertility. Int. J. Gynaecol. Obstet. 1991; 35(1):111.

23. G. Schaefer. Female genital tuberculosis. Clin. Obstet. Gynaecol. 1976; 19(1): 223-39.

24. V. Falk, K. Ludviksson, G. Agren. Genital tuberculosis in women. Analysis of 187 newly diagnosed cases from 47 Swedish hospitals during the ten-year period 1968 to 1977. Am. J. Obstet. Gynecol. 1980; 138(7 Pt 2): 974-7.

25. N. Gupta, J.B. Sharma, S. Mittal, N. Singh, R. Misra, M. Kukreja. Genital tuberculosis in Indian infertility patients. Int. J. Gynecol. Obstet. 2007; 97: 135-138.

26. A.H. Kolk, A.R. Schuitema, S. Kuijper, J. van Leeuwen, P.W. Hermans, J.D. van Embden, et al. Detection of Mycobacterium tuberculosis in clinical samples by using polymerase chain reaction and a non radioactive detection system. J. Clin. Microbiol. 1992; 30(10): 2567-75.

27. M.W. Langendam, M.J. vander Werf, E. Huitric, D. Manissero. Prevalence of inappropriate tuberculosis treatment regimens: a systematic review. Eur. Respir. J. 2012; 39(4): 1012-20.

28. T.M. Shinnick. The 65-kilodalton antigen of Mycobacterium tuberculosis. J. Bacteriol. 1987; 169(3): 1080-8.

29. J. Agarwal, J.K. Gupta. Female genital tuberculosis-a retrospective clinicopathologic study of 501cases. Ind. J. Pathol. Microbiol.1993; 36(4): 389-97.

30. R. Figueroa-Damian, I. Martinez-Velazco, R. Villagrana-Zesati, J.L. Arredondo-Garcia. Tuberculosis of the female reproductive tract: effect on function. Int. J. Fertil. Menopausal Stud.1996; 41(4): 430-6.

31. R. Rozati, R. Sreenivasagari, C. NagaRajeshwari. Evaluation of women with in fertility and genital tuberculosis. Ind. J. Obstet. Gynecol. 2006; 56: 423-426.

32. R. Punnonen, P. Kiilholma, L. Meurman. Female genital tuberculosis and consequent infertility. Int. J. Fertil.1983; 28(4): 235-8.

33. V. Sivanesaratnam, B.H. Lim, S. Sivanesan, A. Menon. Pelvic tuberculosis: an uncommon gynaecological problem in Malaysia. J. Trop. Med. Hyg. 1986; 89(4): 167-9.

34. S. Weerakiet, A. Rojanasakul, M. Rochanawutanon. Female genital tuberculosis: clinical feature sand trend. J. Med. Assoc. Thai. 1999; 82(1): 27- 
32.

35. K. Deshmukh, J. Lopez, A.K. Naidu, M.D. Gaurkhede, M.V. Kasbawala. Place of laparoscopy in pelvic tuberculosis in infertile women. J. Obstet. Gynecol. Ind. 1987; 37(2): 289-291.

36. V.G. Deepjyoti, K. Mishra, N. Agarwal, S. Gupta. Isolation of Mycobacterium from cases of infertility in women. J. Obstet. Gynaecol. Ind. 1990; 40(6): 803-805.

37. P. Chakraborthy, S. Bhattacharya, S. Adhya, P.K. Mitra, B. Sarker, G.K. Das, K.C. Mitra. Tuberculosis of endometrium. A clinicopathological and Bacteriological study. J. Obstet. Gynaecol. Ind.1993; 43(1): 86-92.

38. Roy, S. Mukherjee, S. Bhattacharya, S. Adhya, P. Chakraborty. Tuberculous endometritis in hills of Darjeeling: a clinicopathological and bacteriological study. Ind. J. Pathol. Microbiol. 1993; 36(4): 361-9.

39. M. Manjari, S. Khanna, U. Arora, S.K. Kahlon, V. Gulati, Pushpa, S.S. Kahlon. Tuberculous endometritis in sterile females: A clinicopathological and bacteriological study. Ind. J. Tubercul. 1995; 42: 227-228.

40. M. Abebe, M. Lakew, D. Kidane, Z. Lakew, K. Kiros, M. Harboe. Female genital tuberculosis in Ethiopia. Int. J. Gynaecol.Obstet.2004; 84(3): 241-6.

41. N. Gupta, J.B. Sharma, S. Mittal, N. Singh, R. Misra, M. Kukreja. Genital tuberculosis in Indian infertility patients. Int. J. Gynecol. Obstet. 2007; 97: 135-138.

42. Y. Yang, M. Hao, Y. Zhu. Laparoscopic diagnosis of tubal infertility and fallopian tubelesions. Zhonghua. Fu. Chan. Ke. Za. Zhi. 1996; 31(6): 327-9.

43. V.K. Arora, R. Gupta, R. Arora. Female genital tuberculosis-need for more research. Ind. J. Tuberc. 2003; 50:9.

44. V. Kulshrestha, A. Kriplani, N. Agarwal, U.B. Singh, T. Rana. Genital tuberculosis among infertile women and fertility outcome after antitubercular therapy. Int. J .Gynaecol. Obstet. 2011; 113(3): 229-34.

45. U.N. Jindal. An algorithmic approach to female genital tuberculosis causing infertility. Int. J. Tuberc. Lung Dis. 2006; 10(9): 1045-50.

46. M.J. Jassawalla. Genital tuberculosis. A diagnostic dilemma. J. Obstet. Gynecol. Ind. 2006; 56(3): 203-204.

47. S. Goagte, S. Joshi, A. Gogate. Tubal factor in infertility-endoscopic and microbiological evaluation. J. Obstet. Gynecol. Ind. 1994; 44: 282-85.

48. R.L. Sweet, J. Mills, K.W. Hadley, E. Blumenstock, J. Schachter, M.O. Robbie et al. Use of laparoscopy to determine the microbiologic etiology of acute salpingitis. Am. J. Obstet. Gynecol. 1979; 134(1): 68-74.

49. S. Agarwal, B.M. Agarwal, D. Nandan, S. Sinchal. Role of Laparoscopy in clinically suspected cases of genital tuberculosis. Ind. J. Obstet. Gynecol. 1987; 846-50.
50. R. Misra, S.P. Sharma, R. Jina, N. Pant, D.K. Srivastava. Female genital tuberculosis with special reference to sterility in Eastern UP. J. Obstet. Gynaecol. Ind. 1996; 46(1): 104-109.

51. S.P. Gupta. Statistical Methods. Sultan Chand \& Sons, 2000.

52. S. Kwok, R. Higuchi. Avoiding false positives with PCR. Nature. 1989; 339(6221): 237-8.

53. N. Singh, A.K. Sharma, V. Dadhwal, N. Gupta, S. Mittal. Post-operative flare-up of genital tuberculosis: a clinical reality. Int. J. Tuberc. Lung Dis. 2008; 12(8): 981-3.

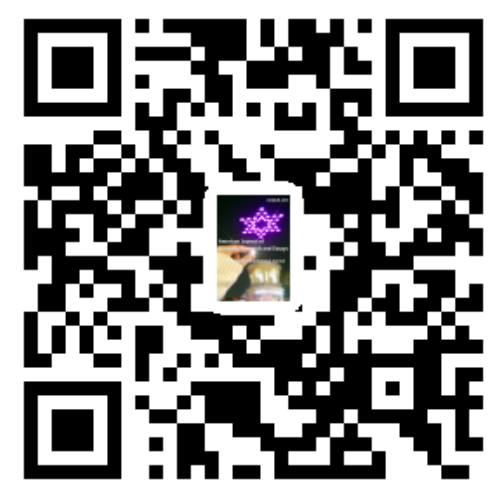

